\title{
Narratives of Access: A Critical Exploration of How Institutional Interactions with Students Affect Regional Student Participation in Higher Education
}

\author{
Jenny Ostini \\ University of Southern Queensland, Australia \\ Helen Partridge \\ Deakin University, Australia \\ Kate Kelly \\ Southern Cross University, Australia \\ Sue Owen \\ Federation University, Australia \\ Sandra Jeffries \\ University of the Sunshine Coast, Australia
}

\begin{abstract}
This article examines the narratives that drive university staff understanding of the concerns and experiences of regional and remote students at five universities in Australia. Interviews were conducted with thirty university staff members over a period of three months in 2018. Reflexive thematic analysis of the stories told by staff of supporting regional students found that staff used the lens of access to create meaningful stories for themselves and others in how they supported students. Access is defined as a multi-faceted term encompassing access to people, Internet, study materials and equipment and study environments. Access is facilitated by a sense of belonging or identity as a student and limited by the lack of this. Our analysis of "belongingness" draws on Bourdieu's concepts of habitas to start to unpick the interactions between higher education institutions and the student that develop student identities as scholars and centres the narrative on the student as a person, wrestling to gain many forms of access within complex social situations.
\end{abstract}

Keywords: Access; equity; narrative; rural and regional students.

\section{Introduction}

In Australia, equity group students' participation in higher education has increased markedly between 2008 and 2015 , but participation by regional, rural and remote students (hereafter regional) has not increased at the same rate and has in fact, fallen as a proportion of undergraduate enrolments (National Centre for Student Equity in Higher Education [NCSEHE], 2017; Vichie, 2017). Much work is done at the policy level around measuring participation, but there is less work on how universities as institutions, and the individuals within these institutions, understand and meet the needs of regional students. Assumptions about or perceptions of issues faced by students can lead to a "gap in our "diversity response" (NCSEHE, 2017, p.5) that has real impacts on services and support provided by universities to regional students. 
This gap in diversity responses motivated a research project to look at innovative ways in which regional equity students in higher education could be supported. In 2017-2018, a group of five Australian regional universities collaborated to start to research this question led by the University of Southern Queensland. The goal of the collaboration was to examine ways that universities could work with public libraries to address some of the needs of their regional equity students. Public libraries were chosen as the focus for the study because Australia has 1,631 public library service points and many of these are in regional areas (National and State Libraries Australasia, 2017). The aim of this article is to explore how university staff perceive their role in the provision of education to regional students and to understand university staff perceptions of factors and influences that lead to student success. By examining the stories they tell about supporting students, themes and narratives within these stories can provide insight into how and why support is crafted for students and potential service gaps.

\section{Literature Review}

Thinking about the field of higher education can be backgrounded with a brief examination of how regional university students are portrayed and the foregrounding of institutional concerns in the literature. The concept of "field" is used in the sense of a specific social sphere of activity with its own norms, which Edgerton and Roberts (2014) describe as "characterised by their own particular regulative principles - the 'rules of the game' or 'logic of practice' - which are subject to power struggles among different interests seeking to control the capital (and 'rules') in that field" (p.195). Much literature in the area of success for regional students focuses on student retention, using an institutional lens to understand the complex motivations and behaviours that ensure success (James, Krause \& Jennings, 2010; NCSEHE, 2017; Stone, 2017). More recently, work has focused on emotional and social aspects of becoming a student and developing a student identity (Aird, Miller, van Megan \& Buys, 2018; Kahu \& Nelson, 2018; Parkes et al., 2015). These two seemingly opposite approaches are both important but only within the context of sites of institutional interaction where student and staff experiences are articulated. Our exploratory research focuses on staff experiences at this point of institutional interaction.

\section{A Focus on Student Success and Retention}

Evidence suggests that retention is less of a concern for regional students than access to higher education itself (Naylor, Baik \& James, 2013; Stone, 2017; ) and that the barrier is participation, not retention (James et al., 2008). Naylor et al. (2013) suggest that:

\footnotetext{
There remain widespread beliefs, often tacit, that allowing more educationally disadvantaged people will lead to higher attrition rates or a lowering of academic standards in order to achieve successful completions... Once at university, low SES students are not substantially less likely to successfully complete their studies, having approximately $96 \%$ of the retention and success rates of domestic students overall. (p.6)
}

James et al. (2010) also find that there is a link between financial hardship and student retention that might be more pronounced for regional students. This link is questioned by Aird et al. (2010) who suggest that more likely factors might be homesickness, isolation, and stress. Aird et al. also raise the concern that much data collection in educational inclusion in Australia is commissioned research for the government and not peer reviewed.

\section{The Deficit Discourse of Social Inclusion and Creating “Belongingness"}

Social inclusion in higher education is often driven by a deficit discourse (O'Shea, Lysaught, Roberts \& Harwood, 2016). This centres on those students deemed to be 'non-traditional' (O'Shea et al., 2016; Smit, 2012) defined in terms of "preparedness, socioeconomic status and geography" (Dawson, Charman \& Kilpatrick, 2013, p.706). The nomenclature "rural, regional and remote" encapsulates many of these multiple disadvantages of geography, economics, and lack of social and emotional "belongingness" (Dawson et al., 2013). O'Shea et al. (2016,) drawing on Bourdieu's ideas of habitas and institutionalisation describe the notion of "social positioning as intrinsic to the nature of educational experience" (p. 324). Edgerton and Roberts (2014) argue that many people using Bourdieu in education see "culture as a marker of class position" instead of a more nuanced understanding of cultural capital as the "situated frame through which we meet our world" (p. 197). For students that may mean that whatever their class status, two things may occur - that they bring a particular regional lens to understanding who they are in the university context, and universities may develop institutional and individual responses that situate all regional students in a particular frame. If we use this approach we can understand that being a regional student is strongly linked to social positioning as an outsider in higher education, regardless of other individual attributes, if that institution is organised to reward 
the characteristics - or what Edgerton and Roberts call the "dispositions and competencies" (p.199) - of traditionally middle class urban students. It is not simply extrinsic barriers but intrinsic and complex factors that confront students (James et al., 2008). Edgerton and Roberts argue that the more congruent the habitas, that is, if there is a high degree of "habitas-field congruence" the higher the likelihood of educational attainment in formal settings (p.199). For regional university students, institutional settings offer low field congruence in terms of organisation, language and ways of doing/being that require students to change or adjust significantly in order to achieve success. The deficit discourse tends to focus on individual "non-traditional" students needing to change to achieve success and less on institutional obligation to identify and address this habitas-field incongruence.

O'Shea et al. (2016) argues that "how academic staff perceive their role in this process [of institutional habitas that perpetrates inequalities] and their perspectives on inclusivity remain ill-defined" (p. 325). It is hoped that the interviews and qualitative analysis here can provide insight into staff perceptions of roles and their approaches to inclusivity that may contribute to a greater alignment of habitas with field that will in turn lead to higher tertiary education success.

\section{Examining Institutional Interfaces Between Students and Universities}

Kahu and Nelson (2018) position as central an understanding of the "educational interface at the intersection of the student and their characteristics and background, and the institution and its practices" (p.59) This interface is again framed as a deficit by some scholars using phrases such as "multiple lifestyle commitments that interfere with study" (Zeldenryk \& Bradley, 2013, p.315). Others frame it as an intercultural exchange where students learn new rules and ways of operating outside of their previous experience, a new habitas. Dees (2006) refers to this process as "student immigrants" and argues:

The university classroom, through power relationships that are constructed through cultural norms such as grading, classroom expectations, and professor-student relationships, becomes a cultural system with hidden rules that may be difficult for students to negotiate. (p.2)

In today's universities, technology is often at the heart of the interface offering "common affordances - expanding connectivity of people and resources, accelerating users' speed of action, and allowing people to interact and collaborate across great distances, both synchronously and asynchronously" (Wozniak, Ellaway \& de Jong, 2018, p. 431) while also simultaneously framing access to resources. However, the domain of technology as the answer to engagement are not the only things to consider in understanding access to the things students need for success in higher education. Additionally, technology is not the answer to distance. Robinson (2012) suggests "Distance education is not always an attractive option for those from low SES backgrounds who lack already-formed academic habits" (p.79). Technology itself, the platforms, language used on and about those, assumptions regarding supply of and access to technology and associated resources, can all be barriers to student, and even institutional success.

The focus in literature on student retention in terms of a deficit discourse on the part of students and institutions ignores the role played by how university staff position themselves in the narrative of student success. It is here that this article seeks to contribute.

\section{The Research Project}

\section{Research Aim}

The aim of this article is to explore through an interpretive lens how regional low-SES university students' study and learning needs are supported by university staff, including any issues or challenges faced, and how university staff perceive their role in the provision of education to regional students and to understand university staff perceptions of factors and influences that lead to student success. By examining the stories, they tell about supporting students, themes and narratives within these stories can provide insight into how and why support is crafted for students and potential service gaps.

To address this gap in literature, five regional universities partnered to explore how Australian universities and public libraries can work together to deliver accessible, relevant, and sustainable learning support to meet the needs and success of regional low-socioeconomic (SES) university students. Data was gathered through semi-structured interviews with 19 public librarians 
and 42 university students from 17 regional low-SES communities, and 30 university staff from five regional universities involved in supporting students in the regional communities. This article will present the findings from the university staff who participated in the project.

\section{Conceptualising Student Success}

For this research project, student success was defined as the combination of both the traditional and holistic understandings of student success:

- Students experiencing positive psychological well-being, community (Schreiner, 2010), and belonging within their peers, courses, and university (Naylor, 2017; Picton et al., 2018);

- Students engaging in satisfying and purposeful educational activities, leading to skill and knowledge acquisition producing academic achievement (Kuh et al., 2006);

- Engagement, achievement, and belonging combining to allow students to persist towards attaining their desired educational outcomes, leading to increased retention and completion rates (Tinto, 1993; York et al., 2015).

\section{Participants}

Participants were sought from each of the five participating institutions through advertising and personal contacts. Each institution had different processes for allowing recruitment of staff, for example, some allowed direct recruitment through personal contacts, others sent out emails to an "all-staff" email list while others only permitted advertising in the staff weekly newsletter. On the basis of this varied access to staff, sampling used mixed approaches: purposive by selecting "informationrich cases" or participants (Palinkas et al., 2015; Russell \& Gregory, 2003;); and opportunistic (also known as emergent) which employed a snowballing approach whereby participants recommended colleagues who they knew were interested in issues of regional students. Rapley (2014) calls the qualitative approach to sampling "sampling-in-action" that focuses on "specific people, situations or sites because they offer a specific - 'biased' or 'information-rich' perspective”' (p. 50). Using this approach researchers sought to balance selection of research participants between professional and academic staff, to use personal contacts where possible and to work with team members in each institution to recruit participants.

Of the 30 participants, 14 were teaching academics, 11 were librarians (liaison, research and front desk) and five participants were academic support service or management personnel. Eighteen women and 17 men participated. Interview transcripts were de-identified.

\section{Data Collection}

The purpose of this project was to explore and understand the ways people experience a particular phenomenon and consequently an interpretive qualitative approach was employed. This approach views data not "as evidence of the truth or reality of a situation, but rather a context-bound subjective insight from the participants" (Nathan, Newman \& Lancaster, 2019, pp. 391-393). Subjective insights are important because how university staff members talk about student experiences shapes not only the services offered and decisions made, but also the very nature of interaction and creation of a culture at the interface of institutions and individuals.

The stories people tell provide insight into how these narratives can be reworked at an institutional level to deliver practical service changes. A study of this kind is by nature exploratory, where the goal is to gather data through semi-structured interviews that can then be interrogated to identify "dominant patterns of meaning surrounding particular phenomena" (Braun et al., 2019, p. 850). The research question driving this study was whether patterns existed in the ways university staff understand the study and learning needs of the low-SES and rural university students that affect the ways in which they support students. Can understanding these patterns of meaning provide insight as to how universities support regional students?

Semi-structured interviews were conducted using Skype, Zoom or telephone and were recorded and transcribed verbatim. Questions were semi-structured and open-ended to allow participants to contribute from their area of experience. The interpretive qualitative framework guiding this study allowed for exploration of "context-bound subjective insight" about participant's experiences in supporting students (e.g. tell me how you support students in your role) and their understanding of 
how much students and staff knew about resources to support student learning (Nathan et al., 2019). Further questions asked about staff knowledge about public libraries and both their own and student use of them. The questions were intentionally openended to draw out participant's stories of how they understood their own work and how they articulated their understanding of their students for others.

\section{Data Analysis}

The interview data was analysed manually using Braun and Clarke's (2006) thematic analysis methodology - a core approach to analysing qualitative data. Thematic analysis was used with an intention to present a rich, detailed, yet complex thematic portrait of the experience of using information to learn among people from refugee background. Such a thematic portrait aims to provide a base for comparing and contrasting the different ways in which university staff understood the study and learning needs of low-SES regional students as well as their role in providing support and advice. It is noted that the same analysis approach was applied in the analysis of the data related to the public library staff (Power et al., 2019) and low SES regional students within the broader project.

After familiarising with the data which involved deep reading and re-reading the data, 306 initial codes were generated in total. The codes reflected interesting features of the data across the whole data set. Through a recursive search for patterns of meaning in and across the entire data set and among codes, similar codes in meaning were identified and collated to create potential themes. In conducting the search, both the relationships between codes and emerging themes were intended to ensure themes were distinctive enough. Each theme was then refined, defined and assigned a descriptive name. This resulted in one meta theme which portrays how university staff understood low-SES regional students' study and learning experiences and needs.

\section{Findings}

Reflexive thematic analysis of interview data of 30 university staff members from five regional universities suggests that staff understand their experiences through a lens of "access". The concept of access - as something for which one has the ability, right or permission, or even something that can be granted to others - allows a critical understanding of the ways institutional interactions with students can be changed to increase regional student participation in higher education. This use of the concept of access is different to the mainstream, or jargon, usage of access in higher education, which focuses on who is able to gain entrance to higher education (James et al., 2008; Neave, 1989). It is a more encompassing concept that includes participation, access to resources and agency to find and use resources. In short, the "cultural toolkit" of "behavioural repertoire (practices)" is the social and economic capital needed to succeed in the specific field of higher education (Edgerton \& Roberts, 2014, p.197).

Access as a dominant theme links the components driving staff narratives about the student-institution interface. Using the lens of access, understood as a constant balancing act between competing needs and desires at the interface of students and institutions (Neave, 1989), allows interrogation of notions such as access to resources, the ways in which access is facilitated and impeded and enables explanation of other findings such as the ways multiple disadvantage and possession of key literacies affect access to resources. Focusing on access as a meta-theme allows consideration of variations within institutions around understanding the narratives of participation as socially constructed negotiations about class and status (Archer, 2003): asking "who gets access to what, on what basis and for what purpose?"

Archer (2003) further reminds us that the "recursive link between structures and identities means that aspects of institutional cultures will have implications within working-class individual's personal identity construction" (p. 14). By looking at staff perceptions, contained within the stories they choose to tell, some of these successive iterations of ideas can begin to be unpacked.

\section{Access to People}

Social and intellectual capital at higher education institutions remains centred on people. Knowing who to talk to and successfully making connections within the institution is crucial to accessing other resources.

Across the participating institutions, staff contact with students is mainly through email, followed by telephone, Facebook (official course or university site), the library (including live chat) learning management system, social media generally, through 
unofficial forums (such as student Facebook communities), SMS, and a few who still contact the university by letter mail. What underlines all of these methods of contact between students and universities is the continued importance of face-to-face delivery of service and support. Increasingly service is delivered via online means such as online tutorials or Zoom or Skype sessions. Much of this access depends on students taking the initiative. Sometimes approaching the course coordinator, lecturer or tutor is not enough if that person is not aware of learning resources. One participant described the roles as: "Academics are academics and they are there to teach. Support services are support services and they're there to support. They don't mix." (Participant 3 )

This "not-mixing" can have direct implications for students who may not be referred on from their first point of contact to the needed support services or find the structures too complex and fail to follow up themselves.

The level of support received by students can be entirely based on "that relationship between the library staff, the researchers and the educating staff." (Participant 16) Another participant (27) noted they "would be surprised if more than half of the academic body uses the specifics of the resources available at the library or at the learning and teaching team."

Interesting is the extent of reliance on live chat both to directly address information enquiries and to refer students to other assistance available. For some students, this is one of the few ways they can directly contact people at their institution for immediate information. In some ways this reliance on live chat is how students "hack" the wider university systems that are designed for administrative efficiency. Further research might illuminate the pressures this may place on library staff, who usually host live chat sessions, to address service or information gaps across the university.

Access to people is about having the social, emotional and other resources to know to whom concerns need to be addressed or through whom resources are able to be accessed. One university staff member framed it as:

And they are coming from a wide range of backgrounds....and there's such a lack of support structures in place that a lot of students get affected in more than one area. And disadvantaged - I don't like to use that word - but they're unable to get that support that they need, whereas students in the city or metropolitan areas, you can usually find an academic tutor, or you can find somebody else, friends or other members of family that have been to university and can give you that information. (Participant 15)

Social capabilities and emotions that may affect ability to access people include isolation, embarrassment, anxiety and frustration. One participant reported that: “... we know that they're quite anxious, even just to come to a one-on-one, basic computer session because it's asking them, I guess to let the world know - they see that they don't have those skills." (Participant 20)

A particular issue for access to people is that distance is seen to exacerbate small issues and that students were reluctant to ask for, and in many cases, did not know about, or feel entitled to, the extra assistance that they needed, "I spend a lot of time telling students about what's available and how I can support them and how other people can support them, because there's not that great expectation." (Participant 14)

Remote students face barriers not experienced by on-campus students in accessing people resources. Remoteness compounded by other disadvantage has been shown to decrease student participation and success (James et al., 2002), in part because of social capacity and belief in entitlement to access:

They feel that if they do come into it, they feel secondary, like second class citizens - that puts them on the back foot. They feel like they're constantly asking. It's not the same kind of confidence thing as it is for students who understand the language already. (Participant 25)

\section{Access to Institutional Resources}

University staff realise that issues for regional low SES students are not just about individual struggles with literacies. There are systemic institutional issues at play including technology system barriers driven by regular technology platform changes. Even simple platform changes such as locations of information being moved on the learning management system can led to information access difficulties. 
Information architecture and structural barriers exist that arise from university design of systems to serve university structures, policies, strategies and even marketing, which means that information can be hard to locate. For example, a student may find it impossible to locate the same person to whom they spoke about their concerns in the past because all student assistance requests are triaged through an online centralised customer service system. This serves the university needs of being able to resource and staff student contact points but makes continuity and service difficult for individuals:

And I think, what happens is that they go to Study Desk and they know they've seen a link somewhere, and so they end up going around and around in Study Desk or some other part of the ... architecture. And they get lost in a room somewhere, where there's ... no windows. (Participant 9)

I think it just goes with the whole ... you know, students coming into an academic environment, they're new to it and they're not necessarily technologically savvy. So navigating through a homepage where they have to find all their resources, know how to join discussion groups and get onto that Blackboard site, or whatever it is they're using for their live tutorials or lectures, all of that can be quite confusing for them - and where to find things, how to keep up to date with weekly announcements and discussions with their peers on their discussion boards... can be quite overwhelming for them. (Participant 17)

Linked to this is the perception that institutions "gate-keep" information and do not engage with communities or with students, in fact, often actively limit community access to institutional resources:

I do not understand why we require the students to know where to go and how to frame their question. I would like to see students able to just come into a central service point in a university where they can type in or ring up and ask their question. (Participant 25)

In terms of resources, staff generally agreed that the issue is not a lack of resources for universities, but lack of knowledge about the existence of resources on the part of individuals. Staff also spoke passionately about the need to find new ways of engaging with students that are not condescending but instead meet with student's needs. It becomes not just about what the institution wants students to know, but what students need and want to know in their study and interactions with the university:

I think it's just about how we make them [resources] accessible to students, and more than that, how we give them to students, or the way we relate to students in the way that we share those resources. There has to be some reason for them to watch them or to listen to them. And if we care about them, then so do they. (Participant 14)

There was a strong sense among the participants that students who accessed learning resources the most were often not those most in need of help - that those who knew most about the system were more able to take advantage of resources than other students. Disadvantaged students not only are less aware of resources, but are not confident in their belief that they are entitled to them: "And it's the students who are the least well-equipped or well-versed in the practice of higher education or learning, that are the least likely to ask for help" (Participant 19).

\section{Access Through Multiple Literacies}

Literacies are about students knowing what to do, how, when, and efficient ways to maximise outcomes. Access to resources may be limited by inadequacies of academic, social and information literacies. Academic literacies are the social practices of academic disciplines, the ways of writing and talking that demonstrate competence, familiarity and belonging (Lea \& Street, 2006). Information literacies are the specific skills required to find, critically analyse and use information. (CILIP, 2018). They can also be defined in terms of individuals "being able to draw upon different ways of experiencing the use of information to learn" (Partridge, Edwards \& Thorpe, 2010, p. 276). Digital literacies are the "the capabilities which fit someone for living, learning and working in a digital society" (Jisc, 2015).

Participants framed student academic struggles in the context of lack of these literacies and poor educational backgrounds (a deficit on the part of students) compounded by widespread use of academic jargon within universities (institutional deficits). For students who may already feel that they do not belong in an educational institution, the ways in which universities present information and the language that they use can be a barrier to learning and to continuing. As one participant puts it, "Most of our staff don't understand the emails that come around, let alone the students." A sense of belonging is also discussed by another participant: 
... it took me time when I was at university, to believe I deserved to be at university and that I belonged at university... And so, if you don't have that understanding of the pathway that a student coming from a remote, rural, background is having to deal with in order to just get into university, there's a whole other thing about staying at university as well. (Participant 15)

Participant narratives identified a perception of student reluctance to access online help or ask for help generally, and to engage online. Students are seen to not do readings, to be intimidated by university libraries and to avoid using them. Many students are perceived to dislike face to face contact and being contacted by telephone. This is the student deficit model in full flow. It is clear that disadvantaged students don't have an expectation of service, that is, they do not believe that there are services or help available for them to access. This may be a particular feature for regional students:

I believe only a very small percentage of our students actually contact us. And some of that may be because the majority of our students are online, and therefore don't walk past the building, so it doesn't prompt them to think, "Ah, there's a help centre there." And it's very difficult for us to find ways, as for everyone, to draw their attention electronically and say "Hey, you know, we can help." (Participant 25)

\section{Access to Technologies}

Regional disparities in Internet access continue in Australia and are compounded by social, education and other factors (Willis \& Tranter, 2006). The 2017 Australian Digital Inclusion Index "reveals substantial differences between rural and urban areas. In 2017 digital inclusion is 7.9 points higher in capital cities (58.6) than in country areas (50.7). The overall 'Capital-Country gap' has narrowed slightly since 2015, from 8.5 (2015), to 8.3 (2016), to 7.9 (2017)" (Thomas, et al., 2017, p. 6). It may be understatement to say “... we've got students who are really relying on not the best or most expensive internet accounts."

Internet issues include not only include availability, but also bandwidth, reliability and cost. Of concern are conditions where staff developing content and resources have access to high quality Internet and select online resources accordingly, while students may not be able to reliably access these.

Internet access, both for students and staff, on campus and off, featured strongly in the interviews. Illustrating this, bandwidth was insufficient in regional Queensland areas for video interviewing for some participants in this study:

... they tend to have a lot of connectivity issues because many of them come from regional locations where they just don't have the benefit of the bandwidth. And likewise, when it comes to download capacity, there seems to be some barriers around their ability to download larger files...I try to be mindful of what sort of size the resource is and how accessible it is. And I'm trying to also give them perhaps more than one options when dealing with that resource, so that they can either stream the resource if the resource is embedded; or alternatively, download the resource if bandwidth and download capacity permits. (Participant 4)

Participants in this study reported being aware of student Internet concerns about lack of access, poor quality, access that varied across students leaving some well-resourced and others not, varied access across campus locations (even within the same organisation - a particular issue with centralised printing services which are slow or not reliable for satellite campuses dependent on good linkages with printer servers on central campuses) and the impact of mobile-only access. A very small number had not experienced or heard of any Internet access issues. With online tutorials, one participant reported:

So most of them will have it in their homes, but it's not a good connection, and they drop out, and they'll often say that - and that's both those that are living regionally and even those that aren't. So, there are issues with connecting. But even yesterday, as an example, I was running my online tutorial and...3 of them, kept dropping out and had to keep coming back in, and there is one student that constantly keeps coming in and out and has been since the beginning of the session. (Participant 13)

This is a significant concern as institutions address service delivery to regional students by moving materials and resources online. Support staff report that substantial portions of their work is working with academics to ensure courses and course materials are not bandwidth-heavy, and with students to find ways they can access online resources:

... there's a lot made on making your courses look nice and flashy...They also use a lot of bandwidth. There's more and more pressure to do stuff online, to have a wider student basis, but students are constantly running into issues where they can't access certain software, their computers can't access particular aspects of the site, or the site comes up peculiar. (Participant 1) 
Other resources to which students lack access are technology equipment, such as computers and printers, textbooks and study environments -envrionments that are a physical and emotional space: "having a space to come to, like another home in a sense ... away from whatever distractions of home and demands and responsibilities.” (Participant 9). Additionally:

... we all assume that they've got computers at home, and I know that for some, that's a problem...just look at the stuff that we're using right now to do this meeting. And when you add up the cost of that, how realistic is it just to assume that all students will have that? (Participant 24)

Interestingly, staff feel that online teaching both allows diversity (by allowing a wider range of students from different backgrounds to take part in education) and masks disadvantage, through the anonymity of online interactions:

... there are online groups, a lot of them feel like they can hide behind that, whereas disadvantaged groups in the face-to-face,

they actually bubble up to the top and become quite prominent in getting their needs met in a personal way." (Participant 11)

\section{Discussion}

Using the lens of access to understand interactions at the interface of individuals and institutions allows discussion of power and relationships in a way that might not otherwise be possible. For staff, understanding interactions with students as being about access makes the focus on meeting immediate needs, often compelling and urgent. It positions the university and university staff as "problem solvers" and decentres the voice and capabilities of students. If student success is about access, it is something that the holder of power can give to students. Even critical approaches that ask questions about who gets access on what basis attribute power in the relationship to university staff. For staff, such a narrative of access may exist because that is where they feel they have agency to make changes. Ironically, because the lens of access focuses on individual actions, the focus shifts away from institutional and social sites where systemic change might more constructively take place.

A central question of this research was how universities can improve the way regional students are supported. One way is to use a different lens to focus on relationships between information, access and power (Kellner \& Share, 2007). If staff understanding of student experience focuses on access, the emphasis is on who controls and regulates it. This traditionally subjective approach focuses on "human agents and their practices as primary objects of analysis" (Fuchs, 2010, p.174; Giddens, 1984). Even if focus is shifted to a more objective approach that looks at institutionalised relationships such as institutional facilitators and impediments to access, the perspective is still that of those holding power. Consideration of educational institutions as social systems that produce and distribute content that must be consumed in order for the system to continue, means that changes can be made to the dynamics of student-staff interaction. By changing the lens through which university staff understand, narrate and therefore facilitate the experiences of rural, regional and remote students, agency is shifted outside the institution.

The question remains of whether it is possible to change the way institutions think about regional student learning? In the context of this study, changing that lens suggest that two key ideas that must be included in the narratives of success for lowSES students living in regional communities. Both are student-centred and move away from institutional focus on increasing access to a focus on shifting power in institutional relationships towards students. The first is creating a sense of belonging through intentional design of curriculum and support services to increase a culture of inclusion and build a student's sense of identity as a scholar (Working Together, 2018). The second is to centre the student as a person, increasing engagement through understanding the multiple facets of students operating in complex environments. Starting to shift the balance of power at the interface of institutions and students from institutions to students means that more equal relationships can be developed. This may be tied to greater student success and wider participation in processes that are seen to be of long-term benefit for individuals and communities.

The NCSEHE (2017) argues that: "Reversing economic and cultural challenges requires a networked approach to regional economic development in which education plays a facilitating role. Positive community development often springs from building on existing community strengths ..." (p. 15).

To reinforce a social system of education we have to use a narrative that shifts power away from institutions and towards the individuals that consume the products of that institution. The Working Together (2018) project suggests that, in alignment with the NCSEHE's stance, change may come through regional institutions building partnerships with community organisations 
such as public libraries who are already part of regional student identities. Increasing regional student habitas-field congruence through delivery of services and support through public libraries where there is a higher level of familiarity and comfort may increase student academic success. Initiatives such as Country University Centres that build partnerships with already existing community organisations such as Regional Development Australia, commercial entities such as credit unions and state governments can be another approach that helps students study in their own place.

By partnering with community-based organisations, higher education might become more about facilitating success than negotiating and limiting access. Future research needs to investigate the possibilities of collaboration with public libraries and other community organisations to provide support to students and test whether this has an impact on university narratives and on student success.

\section{Acknowledgements}

This work was supported by the Australian Government's Higher Education Participation and Partnerships Program (HEPPP) under Grant HEP1600075 in the National Priorities Pool 2016.

This study was conducted under approval by the following Human Research Ethics Committees: University of Southern Queensland No. H17REA199; Federation University No. [E17-019]; Southern Cross University No. [ECN-17-248]; University of the Sunshine Coast No. [A/17/996]; and the University of New England.

We also thank fellow team members Blanca Pizzani, Leeanne Pitman, Barbara Paton and Emma Power for contributing their time, expertise and advice throughout the research process.

\section{References}

Aird, R., Miller, E., van Megen, K. \& Buys, L. (2010). Issues for students navigating alternative pathways to higher education: barriers, access and equity: A literature review. http://hdl.voced.edu.au/10707/218240

Archer, L. (2003). Social class and higher education. In L. Archer, M. Hutchings \& A. Ross (Eds.), Higher education and social class: Issues of exclusion and inclusion (pp. 5-20). Routledge Falmer.

Braun, V., \& Clarke, V. (2006). Using thematic analysis in psychology. Qualitative Research in Psychology, 3(2), 77-101. https://doi.org/10.1191/1478088706qp063oa

Braun, V., Clarke, V., Hayfield, N. \& Terry, G. (2019). Thematic analysis. In P. Liamputtong (Ed.), Handbook of research methods in health social sciences (pp.843-860). Springer Nature. https://doi.org/10.1007/978-981-10-5251-4_103

CILIP. (2018). Definition of information literacy. https://archive.cilip.org.uk/research/topics/definition-information-literacy

Dawson, P., Charman, K., \& Kilpatrick, S. (2013). The new higher education reality: What is an appropriate model to address the widening participation agenda? Higher Education Research and Development, 32(2), 706-721. https://doi.org/10.1080/07294360.2013.776520

Dees, D. (2006). "How do I deal with these new ideas?" The psychological acculturation of rural students. Journal of Research in Rural Education, 21(6), 1-11.

Edgerton, J.D. \& Roberts, L.W. (2014). Cultural capital or habitas? Bourdieu and beyond in the explanation of enduring educational inequality. Theory and Research in Education, 12(2), 193-220. https://doi.org/10.1177/1477878514530231

Fuchs, C. (2010). Alternative media as critical media. European Journal of Social Theory, 13(2), 173-192. https://doi.org/10.1177/1368431010362294

Giddens, A. (1984). The constitution of society. University of California Press.

James, R., Baldwin, G., Coates, H., Krause, K-L., \& McInnis, C. (2002). Analysis of equity groups in higher education 19912002. Centre for the Study of Higher Education. https://melbournecshe.unimelb.edu.au/_data/assets/pdf_file/0005/1669892/equity_report_final.pdf.

James, R., Bexley, E., Anderson, A., Devlin, M., Garnett, R., Marginson, S., \& Maxwell, L.

(2008). Participation and equity: A review of the participation in higher education of people from low socioeconomic backgrounds and Indigenous people. https://melbourne-cshe.unimelb.edu.au/research/archived-research/participation-andequity

James, R., Krause, K-L., \& Jennings, C. (2010). The first year experience in Australian universities: Findings from 1994 to 2009. https://www.voced.edu.au/content/ngv\%3A28624 
Jisc. (2015). Developing students' digital literacy. https://www.jisc.ac.uk/guides/developing-students-digital-literacy

Kahu, E. R., \& Nelson, K. (2018) Student engagement in the educational interface: Understanding the mechanisms of student success. Higher Education Research \& Development, 37(1), 58-71. https://doi.org/10.1080/07294360.2017.1344197

Kellner, D., \& Share, J. (2007). Critical media literacy, democracy, and the reconstruction of education. In D. Macedo \& S.R. Steinberg (Eds.), Media literacy: A reader (pp. 3-23). Peter Lang Publishing. https://doi.org/10.2304/pfie.2007.5.1.59

Kuh G., Kinzie J., Buckley J. (2006). What matters to student success: A review of the literature. https://nces.ed.gov/npec/pdf/kuh team report.pdf

Lea, M.R., \& Street, B.V. (2006). The "Academic Literacies" model: Theory and applications. Theory Into Practice, 45(4), 368-377. https://doi.org/10.1207/s15430421tip4504_11

O'Shea, S., Lysaght, P., Roberts, J., \& Harwood, V. (2016). Shifting the blame in higher education - social inclusion and deficit discourses. Higher Education Research and Development, 35(2), 322-336 https://doi.org/10.1080/07294360.2015.1087388

Nathan, S., Newman, C., \& Lancaster, K. (2019). Qualitative interviewing. In P. Liamputtong (Ed.), Handbook of research methods in health social sciences (pp.391-409). Springer Nature. https://doi.org/10.1007/978-981-10-5251-4_77

National Centre for Student Equity in Higher Education (2017) Successful outcomes for regional and remote students in Australian higher education: Issues, challenges, opportuniites and recommendations. (2017). https://www.ncsehe.edu.au/wp-content/uploads/2017/10/Regional-feature-FINAL.pdf.

National State Public Libraries Australasia (2017). Australian public libraries statistical report 2015-2016. (2017). https://www.nsla.org.au/sites/default/files/documents/nsla.aust-pub-lib-stats_2015-16.pdf

Naylor, R., Baik, C., \& James, R. (2013). A Critical interventions framework for advancing equity in Australian higher education. Report prepared for the Department of Industry, Innovation, Climate Change, Science, Research and Tertiary Education. Centre for the Study of Higher Education. https://www.ncsehe.edu.au/wp-content/uploads/2014/09/CriticalInterventions-Framework-20-August-2013.pdf.

Neave, G. (1989). Access to higher education: An overview. Higher Education Policy, 2(1), 7-9 https://doi.org/10.1057/hep.1989.1

Palinkas, L.A., Horwitz, S.M., Green, C.A., Wisdom, J.P., Duan, N., \& Hoagwood, K. (2015). Purposeful sampling for qualitative data collection and analysis in mixed method implementation research. Administration and Policy in Mental Health and Mental Health Services Research, 42: 533-544. https://doi.org/10.1007/s10488-013-0528-y

Parkes, M., Gregory, S., P., Fletcher, Adlington, R., \& Gromik, N. (2015). Bringing people together while learning apart: Creating online learning environments to support the needs of rural and remote students [online]. Australian and International Journal of Rural Education, 25(1), 65-77.

Partridge, H., Edwards, S., \& Thorpe, C. (2010). Evidence-based practice: Information professionals' experience of information literacy in the workplace. In S. Talja \& A. Lloyd (Eds.), Practising Information Literacy (pp.273-298). Chandos.

Picton, C., Kahu, E.R., \& Nelson, K. (2018) 'Hardworking, determined and happy': First-year students' understanding and experience of success. Higher Education Research \& Development, 37(6), 1260-1273. https://doi.org/10.1080/07294360.2018.1478803

Power, E., Partridge, H., Owen, S., Kelly, K., \& Jeffries, S. (2019). Working together: Public libraries supporting rural, regional, and remote low-socioeconomic student success in partnership with universities. Journal of the Australian Library and Information Association, 68(2), 105-125. https://doi.org/10.1080/24750158.2019.1608497

Robinson, S. (2012). Freedom, aspiration and informed choice in rural higher education: Why they are saying "no". Australian and International Journal of Rural Education, 22(2), 79-95.

Rapley, T. (2014). Sampling strategies in qualitative work. In U. Flick (Ed.), The sage handbook of qualitative data analysis. (pp. 49-63). Sage.

Russell C.K., \& Gregory, D.M. (2003). Evaluation of qualitative research studies. Evidence-Based Nursing, 6(2), 36-40. http://dx.doi.org/10.1136/ebn.6.2.36

Schreiner, L.A. (2010). The "thriving quotient": A new vision for student success. About Campus, 15(2), 2-10. https://doi.org/10.1002\%2Fabc. 20016

Smit, R. (2012). Toward a clearer understanding of student disadvantage in higher education: Problematising deficit thinking. Higher Education Research \& Development, 31(3), 369-380. https://doi.org/10.1080/07294360.2011.634383

Stone, A.N. (2017). Rural students and higher education: An overview of challenges and opportunities. Texas Education Review, 5(1), 1-9.

Thomas, J., Barraket, J., Wilson, C., Ewing, S., MacDonald, T., Tucker, J., \& Rennie, E. (2017). Measuring Australia's digital divide: The Australian digital inclusion index 2017. https://doi.org/10.4225/50/596473db69505

Tinto, V. (1993). Leaving college: Rethinking the causes and cures of student attrition (2d ed.) Chicago, IL: University of Chicago Press.

Universities Australia. (2009). Submission into rural and regional access to educational opportunities 
https://www.universitiesaustralia.edu.au/ArticleDocuments/208/Inquiry\%2520into\%2520Rural\%2520and\%2520Regional\%2 520Access\%2520to\%2520Educational\%25200pportunities.pdf.aspx\&sa=U\&ved=0ahUKEwjuZev76_eAhWMOnAKHQHaBT0QFggiMAQ\&usg=AOvVaw2vDW3ONZj3aPkQ1qBk-hzW

Vichie, K. (2017). Higher education and digital media in rural Australia: The current situation for youth. Australian and International Journal of Rural Education, 27(1).

Willis, S., \& Tranter, B. (2006). Beyond the 'digital divide': Internet diffusion and inequality in Australia. Journal of Sociology, 42(1), 43-59. https://doi.org/10.1177/1440783306061352

Working Together. (2018, October 1). Working together: Australian universities and public libraries facilitating student success in regional and remote communities.

Wozniak, H., Ellaway, R.H., \& de Jong, P.G.M. (2018). What have we learnt about using digital technologies in health professional education? The Medical Journal of Australia, 209(10), 431-433. https://doi.org/10.5694/mja18.00152

York, T., Gibson, C., \& Rankin, S. (2015). Defining and measuring academic success. Practical Assessment, Research, and Evaluation, 20(5), 1-20. https://doi.org/10.7275/hz5x-tx03

Zeldenryk, L., \& Bradey, S. (2013). The flexible learning needs and preferences of regional occupational therapy students in Australia. Higher Education Research \& Development 32(2), 314-327. https://doi.org/10.1080/07294360.2012.675572

\section{Please cite this article as:}

Ostini, J., Partridge, H., Kelly, K., Owen, S., \& Jeffries, S. (2020). Narratives of access: A critical exploration of how institutional interactions with students affect regional student participation in higher education. Student Success, 11(2), 60-71.

https://doi.org/10.5204/ssj.v11i2.1334

This article has been peer reviewed and accepted for publication in Student Success. Please see the Editorial Policies under the 'About' section of the Journal website for further information.

Student Success: A journal exploring the experiences of students in tertiary education

(c) (i) Except where otherwise noted, content in this journal is licensed under a Creative Commons Attribution 4.0 International Licence. As an open access journal, articles are free to use with proper attribution. ISSN: 2205-0795 